apnea, aspiration pneumonia, episodic muscular rigidity and near miss SIDS. Nose tapping to elicit the hyperekplexic startle response should be included in the routine examination of newborns. See Ped Neurol Briefs May 1991; $\underline{5}: 36$. The primary pysiological abnormality in hyperekplexia involves spinal as well as brainstem hyperexcitability (Matsumoto J et al. Ann Neurol July 1992; 32:41-50).

\title{
LISSENCEPHALY: CAUSAL HETEROGENEITY
}

Clinical, cytogenetic and molecular studies in 65 patients with isolated lissencephaly sequence (ILS) are reported from Indiana University School of Medicine, Indianapolis; Tufts New England Medical Center, Boston; Eastern Virginia Medical School, Norfolk; University of Washington School of Medicine, Seattle; and Baylor College of Medicine, Houston. All patients had type I lissencephaly of varying severity and a grossly normal cerebellum; $17 \%$ had agenesis of the corpus callosum and $21 \%$ had cavum septi pellucidi. The facial appearance was described as essentially normal, but subtle abnormalities were observed, including microcephaly (71\%), bitemporal hollowing (70\%), abnormal nasal bridge $(49 \%)$, and small jaw (58\%). All were severely mentally retarded, and $76 \%$ had a mixed seizure disorder that progressed to infantile spasms in $35 \%$. Seizures were uncommon during the first few months of life, but opisthotonos was often reported. Hypotonia evolved into spasticity, and feeding difficulties usually improved after several days or weeks. During pregnancy, prolonged or heavy vaginal bleeding occurred in $12 \%$ and flu-like syndromes in the mothers of $12 \%$. CP and MRI appearances showed a smooth cerebral surface with open sylvian region, a typical "figure8 " appearance on axial images and enlarged posterior lateral ventricles (colpocephaly). Molecular studies showed microdeletions in chromosome band $17 p$ (6 patients). Other causes included autosomal recessive inheritance, intrauterine infection and intrauterine perfusion failure. The calculated risk of recurrence in sibs was 7\% (Dobyns WB et al. Causal heterogeneity in isolated lissencephaly. Neurology July 1992; $\underline{42: 1375-1388) . ~(R e p r i n t s: ~}$ Dr. William B. Dobyns, Division of Pediatric Neurology, University of Minnesota, P.O. Box 380,420 Delaware Street SE, Minneapolis, MN 55455.)

COMMENT. For further reports on lissencephaly see Ped Neur Briefs August $1991 ; \underline{5}: 59-60 ;$ June $1992 ; \underline{6}: 48$. The role of human fetal ependyma in the pathogenesis of some cerebral malformations such as lissencephaly/pachygyria and holoprosencephaly is reviewed by Dr. Harvey B. Sarnat in Pediatr Neurol May/June 1992; $\underline{8}: 163-78$. Lissencephaly is a primary disturbance of neuroblast migration associated with abnormal gyration of the cerebral cortex. Ependymal abnormalities include persistence of the fetal pseudostratified columnar organization and subventricular rosettes of ependymal cells. The author provides an excellent account of the pathogenesis of cerebral dysgenesis. (Correspondence after August 15: Dr. Sarnat, Children's Hospital, CH49, 4800 Sand Point Way N.E., Seattle, WA 98105.)

\section{CONGENITAL HYDROCEPHALUS AND SEIZURES}

The frequency of seizures and long-term outcome in 68 children with congenital hydrocephalus not associated with myelomeningocele were 